\title{
Cyclic Nonlinear Behavior of Pile-Deck Connections Using Structural Software Models
}

\author{
Diego Sosa ${ }^{1}$ and Pablo Caiza ${ }^{2, *}$ \\ ${ }^{I}$ Escuela Politécnica Nacional, Facultad de Ingeniería Civil y Ambiental, Quito, Ecuador \\ ${ }^{2}$ Universidad de las Fuerzas Armadas-ESPE, Quito, Ecuador
}

\begin{abstract}
A study of the cyclic nonlinear behavior of a pile-deck connection (characteristic of cargo port structures) is performed using OpenSEES Concrete02 and Concrete07. Advantages and disadvantages are determined by comparison with experimental results obtained in previous works. The parameters considered are: hysteretic energy, secant modulus, and ductility at moderate and severe damage. This work seeks to define whether more complex calculations warrant additional runtime. It is found that Concrete07, in fact, is much closer to the experimental results in terms of ductility. However, the estimates of hysteretic energy and secant modulus are similar in both models. A better vulnerability estimate would be obtained based on more accurate parameters such as ductility, hysteretic energy and secant modulus.
\end{abstract}

Keywords: Concrete, ductility, fibers, hysteretic energy, port structures, secant modulus.

\section{INTRODUCTION}

Previous studies have identified the most vulnerable structural elements of port structures under earthquake attacks. Especifically, the nearshore pile-slab connections of loading and unloading cargo port structures, suffer major damage after a strong earthquake. For this reason, experimental and analytical studies of the behavior of these elements are needed to understand and control their failure mechanisms.

This is an analytical study that seeks to compare experimental results of a pile-slab connection with results obtained using the OpenSees program by the method of the fibers. The proposed model works primarily at bending, and therefore the key materials are both concrete and steel. However, this paper focuses on the concrete and leaves the steel description for a later work. A previous study [1] worked with models called Concrete01, Concrete04, Concrete02 and Concrete 07. The last two models gave the best results. It also needs to be clarified that the original Opensees code of the stress-strain models for concrete has not been changed. The study of concrete cyclic behavior has had a great development in recent years, particularly with regard to their application in fiber models. Among the models documented in the literature the following are mentioned: Sinha et al. [2], who studied the behavior of the plain concrete under cyclic compressive loading. Karsan and Jirsa [3] conducted an experimental study of the strength and behavior of plain concrete under cyclic compressive loads with different level. These authors found that the curves for loading and unloading are located within a general envelope curve. Yankelevsky and Reinhardt [4], created a simple uniaxial

\footnotetext{
*Address correspondence to this author at the Universidad de las Fuerzas Armadas-ESPE, Quito, Ecuador; Tel: 593(2)3989400; Fax: 593(2)2334952; E-mails: pecaiza1@espe.edu.ec; diego.sosac@epn.edu.ec
}

stress-strain model. Mander, Priestley and Park [5] proposed a stress-strain model for concrete under uniaxial compressive and tension loads. They also considered the concrete confined with transverse reinforcement. Chang and Mander [6] proposed a model that represents the hysteretic behavior of confined and unconfined concrete. They use RambergOsgood functions to represent the curves for loading and unloading. They detail a set of rules that represent the complete behavior of concrete under cyclic loading. Elnashai and Martinez [7] modified the model proposed by Mander, Priestley and Park [5], to consider the effect of degradation in the stiffness and strength by cyclic loading action. Bahn and Hsu [8] have done a parametric study and experimental research on the behavior of concrete against randomic compression load histories. Mansour and Hsu [9] conducted a study considering the softening of the concrete compressive strength, caused by a constant tension deformation in the orthogonal direction. The loading and unloading curves are formed by fragments of linear curves. Sima, Roca and Molins [10] proposed a constitutive model for concrete under cyclic loading, for states of tension and compression stresses. They described the degradation of strength and stiffness by cyclic loading, they also considered effects generated by the closing of cracks. The main novelty of their constitutive model is that all the required data can be obtained through conventional monotonic compressive and tensile tests.

The stress-strain concrete models proposed in OpenSees, consider the recommendations of most authors mentioned above, plus some simplifications to improve the execution time within the program.

The contributions that this study is given to the state of the art in the analysis of pile-slab connections are:

- Identify the concrete models that give better results for ductility, hysteretic energy and secant modulus. 
- Check the definitions of critical points in the stress-strain curves of concrete and steel. These points are: visible concrete cracking, steel first yield, substantial and minimal spalling of concrete.

- Adapt the theoretical definitions of stress-strain critical points to the numerical limitations of the concrete stressstrain models.

Importantly, this model works for bending, regardless shear effects, as the experimental results show that it is sufficiently close. The type of cracking is perpendicular to the axis of the structural member and the resultant loss of stiffness will be described from the stress-strain curves of materials in a flat section. 1D models modified by stresses perpendicular to its plane, such as Chang and Mander [6] model, are widely accepted to describe this type of behavior.

\section{BASIC CONCEPTS OF CYCLIC STRESS-STRAIN CURVES OF CONCRETE}

\subsection{Monotonic Loading to Failure and Envelope Curve}

This type of load is increased continuously and controlled by deformation. In the stress-strain curve, each experimental strain corresponds to a calculated stress value. This monotonic loading results in the envelope that is seen in the Fig. (1). In this envelope, the stress reaches a maximum value, and thereafter the resistance decreases as the strain increases.

\subsection{Cyclic Loading, Loading and Unloading Curve}

A load cycle consists of a section for loading and one for unloading. The cyclic loading is formed by several load cycles. Fig. (1) shows the resultant curve that corresponds to various loading and unloading cycles. The values of stressstrain cyclic loading are lower than those of the envelope.

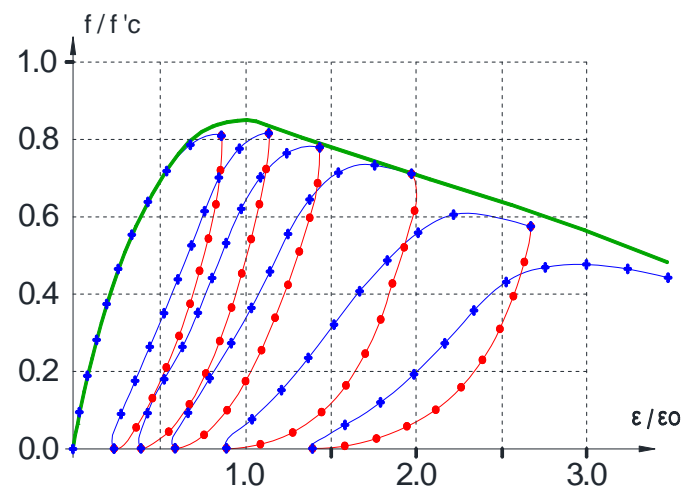

Fig. (1). Normalized stress-strain envelope curve, load and unload.

\section{DESCRIPTION OF THE STRUCTURE}

The studied structure is a cantilever (Fig. 2), representing a slab wharf and pile. Note that this specimen is upside down for ease of implementation and experimentation. This structure is part of a group of tests made at the University of Washington in 2007 [11]. The structure consists of 8 elements; each element has different properties of concrete and reinforcing steel. Concrete properties vary by the amount of transverse steel reinforcement present along the pile body, while the variation of the properties of the steel depends on the anchor and development length. The number of elements was verified with a parametric study. This study determined that a greater number did not change outcomes such as moments, rotations and displacements. It was also found, based on the experimental results, that the damage was concentrated at the first element (E1), see Fig. (2). This means that the nonlinear behavior of the structure depends mainly on E1. Because of its importance, it is worth noting that this element has the following features: It is an element based on the fiber method, and its degrees of freedom are typical of a bending $2 \mathrm{D}$ element (horizontal, vertical and rotational displacement around the axis perpendicular to the plane). It is used to represent the pile-slab connection because being a distributed plasticity element it can represent not only the extent of damage, but also automatically generate its progress. It also includes the effect of geometric nonlinearities (P- $\Delta$ effect).

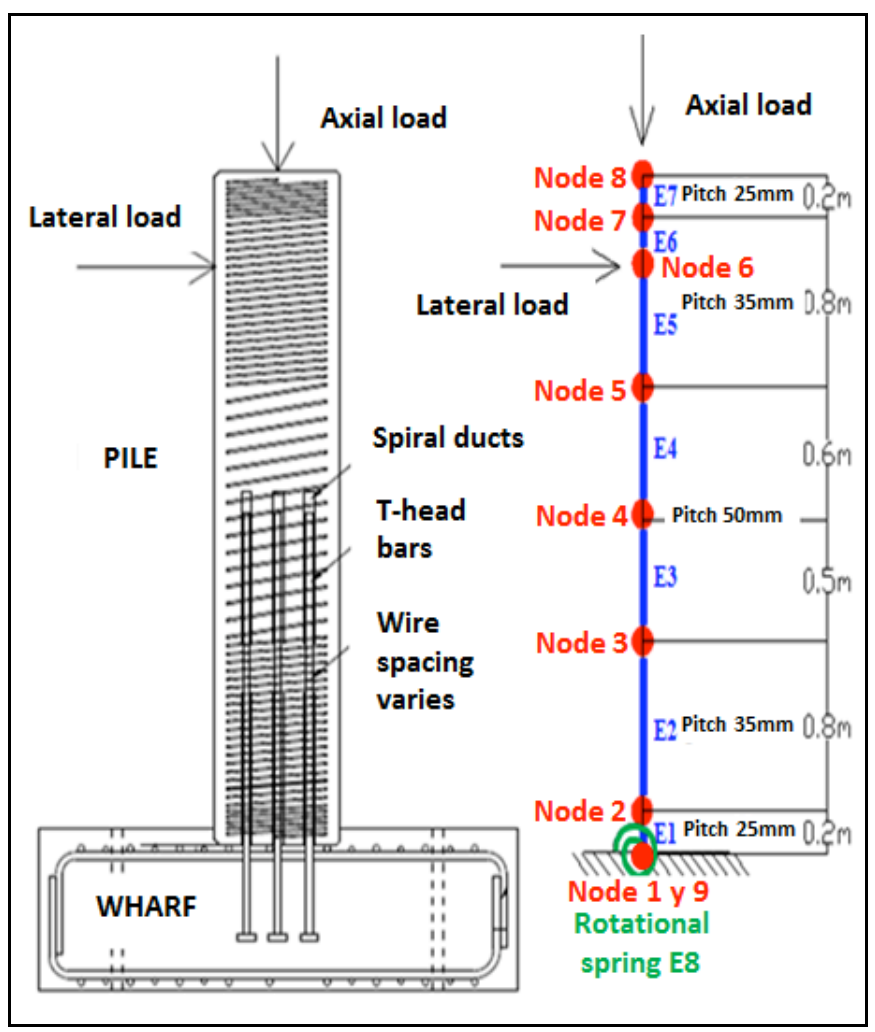

Fig. (2). Structure modeled in OpenSEES. Source: Caiza [12].

\subsection{Concrete}

In Table 1, the properties of the concrete used in this study are presented. In Table $\mathbf{2}$, the properties of confined and cover concrete characteristic of each structural element are presented. These values define the shape of the stressstrain curves of the concrete, as seen in Fig. (3).

The properties described in Table 2 are:

$\mathrm{f}^{\prime} \mathrm{c}$ : maximum compressive strength of concrete.

ec: Strain corresponding to $\mathrm{f}^{\prime} \mathrm{c}$.

$\mathrm{fcu}=$ Residual concrete stress.

$\mathrm{ecu}=$ Strain corresponding to fcu. 
Table 1. Description of general properties of concrete.

\begin{tabular}{|c|c|c|}
\hline & Value & Description \\
\hline \hline Eo & $41216.87 \mathrm{MPa}$ & Modulus of elasticity of concrete \\
\hline Ets & $5308.96 \mathrm{MPa}$ & Tension softening stiffness \\
\hline $\mathrm{ft}$ & $10.62 \mathrm{MPa}$ & Maximum tension strength of concrete \\
\hline et & 0.0002 & $\begin{array}{c}\text { Strain at maximum strength of } \\
\text { concrete in tension }\end{array}$ \\
\hline
\end{tabular}

Fig. (3) shows the variables described in Tables $\mathbf{1}$ and 2. The concrete stress-strain curve is defined from three ordered pairs such as: maximum tensile strength and its deformation (et, $f t$ ), maximum compression strength and its deformation $\left(e c, f_{c}\right)$, residual stress and its deformation $\left(e c u, f_{c u}\right)$.

Fig. (3) shows that Concrete02 and Concrete07 envelope models are identical in the compression segment. Regarding the down section, Concrete02 model is a bilinear simplification, while Concrete 07 has a complex shape controlled by parameters $\mathrm{xn}$ and $\mathrm{r}$.

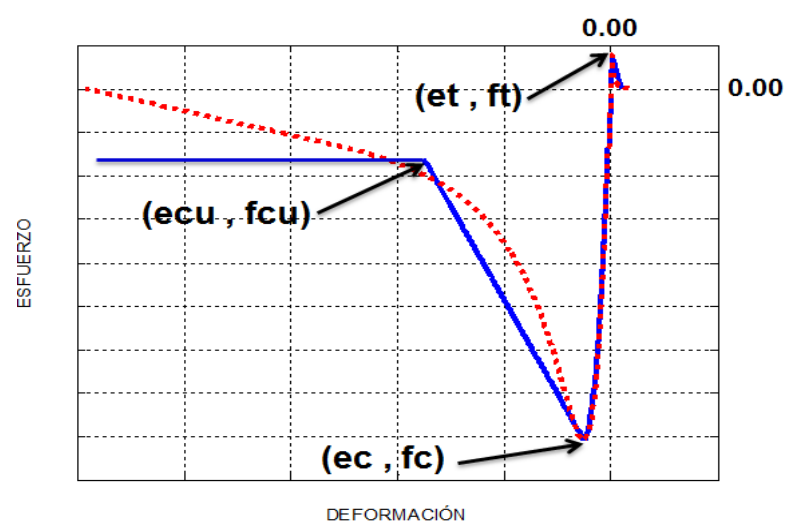

Fig. (3). Diagram of the properties that limit the envelope stressstrain of concrete, Concrete02 (solid line) and Concrete07 (dotted line).

To show the consistency between detailed information in Table 2 and constitutive model parameters, the numerical values of the critical points shown in Fig. (3) have been included in Figs. (8-11).

Table 2. Descrition of the properties of concrete in each element.

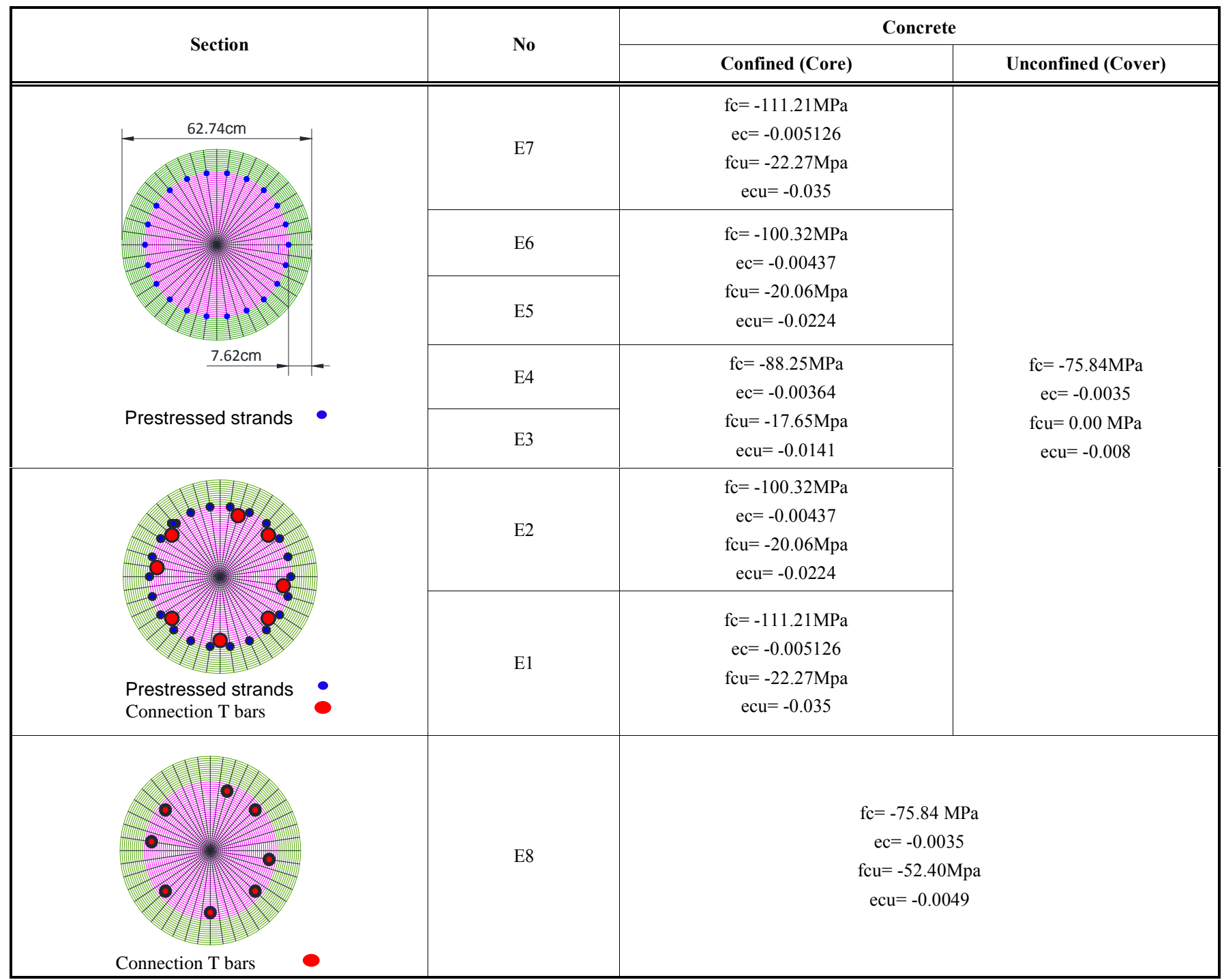


Table 3. Data required to generate the Concrete02 model stress-strain curve.

\begin{tabular}{|c|c|}
\hline \multicolumn{2}{|c|}{ Concrete02 } \\
\hline \hline fc & Maximum compression strength \\
\hline ec & Strain corresponding to fc \\
\hline fcu & Residual stress \\
\hline ecu & Strain corresponding to fcu \\
\hline lambda & Relationship between the slope at ecu and Eo \\
\hline ft & Maximum tension strength of concrete \\
\hline Ets & Tension softening stiffness \\
\hline
\end{tabular}

Table 4. Data required to generate the Concrete07 model stress-strain curve.

\begin{tabular}{|c|c|}
\hline \multicolumn{2}{|c|}{ Concrete07 } \\
\hline \hline fc & Maximum compression strength \\
\hline ec & Strain corresponding to fc \\
\hline Eo & Modulus of elasticity of concrete \\
\hline ft & Maximum tension strength of concrete \\
\hline et & Strain at maximum strength of concrete in tension \\
\hline $\mathbf{x p}$ & $\begin{array}{c}\text { Defines the shape at the end of downhill section of the } \\
\text { envelope in tension }\end{array}$ \\
\hline $\mathbf{x n}$ & $\begin{array}{c}\text { Defines the shape at the end of downhill section of the } \\
\text { envelope in compression }\end{array}$ \\
\hline $\mathbf{r}$ & $\begin{array}{c}\text { Defines the shape at the beginning of downhill section } \\
\text { of the envelope }\end{array}$ \\
\hline
\end{tabular}

Further the necessary variables to completely define the Concrete 02 and Concrete 07 models are shown in Tables 3 and $\mathbf{4}$, respectively. It is observed that there are parameters such as lambda, xp, $x n$ and $r$, which control the shape of the curves. However, the parameters of Fig. (3) define the upper and lower limits of these curves.

\subsection{Steel}

Within the context of this study, focused on the behavior of the concrete, a brief description of steel models becomes necessary. In the pile, it is observed that there are two types of steel, the first is used in the connecting bars pile-slab, the second in the prestressing strands, which are located throughout the pile. For the connecting bars, it is used an OpenSees model called "ReinforcingSteel", and for the prestressing strands the "ElasticPerfectlyPlastic" model. The shape of the envelope of these models is presented in Figs. (4 and 5), respectively.

Data entered into OpenSEES for these steel models are shown in Table $\mathbf{5}$.

In Tables 6 and 7, it is described the data that OpenSees needs to define the steel models used.

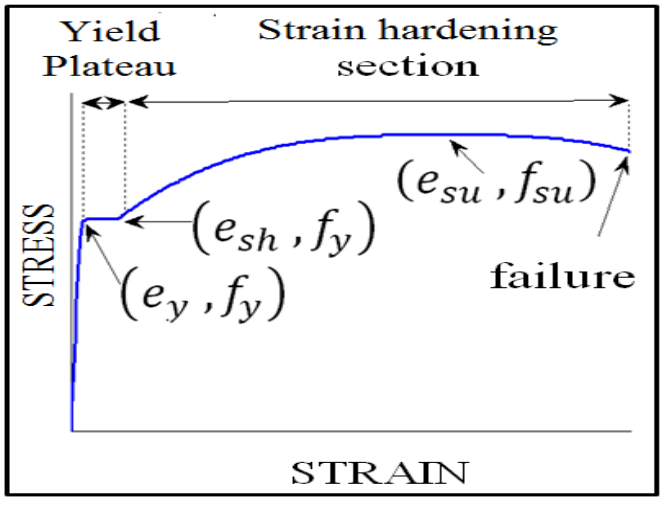

Fig. (4). Envelope of the ReinforcingSteel model.

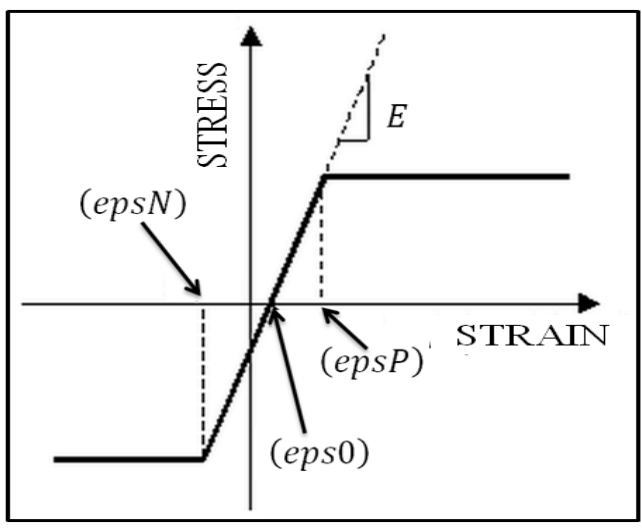

Fig. (5). Envelope of the ElasticPerfectlyPlastic model.

Table 5. Data required to generate the ReinforcingSteel model stress-strain curve.

\begin{tabular}{|c|c|c|}
\hline Element & ReinforcingSteel & ElasticPerfectlyPlastic \\
\hline E7 & --- & $\begin{array}{c}\mathrm{E}=192295 \mathrm{MPa} \\
\text { epsP }=0.0008 \\
\text { epsN }=-0.0004 \\
\text { eps } 0=-0.0008\end{array}$ \\
\hline E5 y E6 & --- & $\begin{array}{c}\mathrm{E}=192295 \mathrm{MPa} \\
\text { epsP }=0.0048 \\
\text { epsN }=-0.0024 \\
\text { eps } 0=-0.0048\end{array}$ \\
\hline E3 y E4 & --- & $\begin{array}{c}\mathrm{E}=192295 \mathrm{MPa} \\
\text { epsP }=0.0078 \\
\text { epsN }=-0.0039 \\
\text { eps } 0=-0.0064\end{array}$ \\
\hline E2 & $\begin{array}{c}f y=489.53 \mathrm{MPa} \\
\mathrm{fsu}=675.69 \mathrm{MPa} \\
E=199948 \mathrm{MPa}\end{array}$ & $\begin{array}{c}\mathrm{E}=192295 \mathrm{MPa} \\
\text { epsP }=0.0048 \\
\text { epsN }=-0.0024 \\
\text { eps } 0=-0.0048\end{array}$ \\
\hline E1 & $\begin{array}{c}\text { Esh }=4482 \mathrm{MPa} \\
\text { esh }=0.0124 \\
\text { esu }=0.132\end{array}$ & $\begin{array}{c}\mathrm{E}=192295 \mathrm{MPa} \\
\text { eps }=0.0008 \\
\text { epsN }=-0.0004 \\
\text { eps } 0=-0.0008\end{array}$ \\
\hline
\end{tabular}


Table 6. Data required to generate the stress-strain curve of the ReinforcingSteel model.

\begin{tabular}{|c|c|}
\hline \multicolumn{2}{|c|}{ ReinforcingSteel } \\
\hline \hline fy & Yield stress in tension \\
\hline fsu & Maximum stress in tension \\
\hline esu & Strain corresponding to fsu \\
\hline E & Initial elastic modulus \\
\hline esh & Strain in which strain hardening begins \\
\hline Esh & Slope of the curve in esh \\
\hline
\end{tabular}

Table 7. Data required to generate the stress-strain curve of the ElasticPerfectlyPlastic model.

\begin{tabular}{|c|c|}
\hline \multicolumn{2}{|c|}{ ElasticPerfectlyPlastic } \\
\hline \hline E & Elastic modulus of the material \\
\hline epsP & Strain in which plastic section in tension starts \\
\hline epsN & Strain in which plastic section in compression starts \\
\hline eps0 & Initial strain (0 by default) \\
\hline
\end{tabular}

\section{LOADS USED}

The model has two types of load, $2001.7 \mathrm{kN}$ vertical and another lateral cyclic consisting of 15 cycles. Each of these cycles consists of a group of sub-cycles. The cycles have been divided into groups, because the scales of the initial and final cycles are very different, as shown in Fig. (6).

The displacement is considered positive when the direction is toward the left, while it is negative when it is toward the right side. Fig. (7) shows the location of the left or right direction of the analyzed section.

\section{CYCLIC STRESS-STRAIN CURVES}

The cyclic stress-strain curves in the fibers model can be obtained for different locations within a cross section. The stress-strain curves of interest are related to the unconfined (cover), and confined (core) concrete material. The most critical location of unconfined concrete is the cover outermost fiber, whereas the critical fiber of confined concrete is the nearest fiber core to the spiral reinforcement in the loading axis. Due to the concentration of damage, the most important experimental results were obtained near the pile-slab interface. Therefore, the analytical results with the OpenSees program are obtained for the element E1 (see Fig. 2). Note that since the model is under cyclic loading and the cross section is not symmetric, the results vary slightly from the right side and left side, this is the reason why it should be identified which value is the most critical.

\subsection{Unconfined Concrete}

In general, the unconfined concrete is one whose physical properties, such as strength and deformation, are not affected
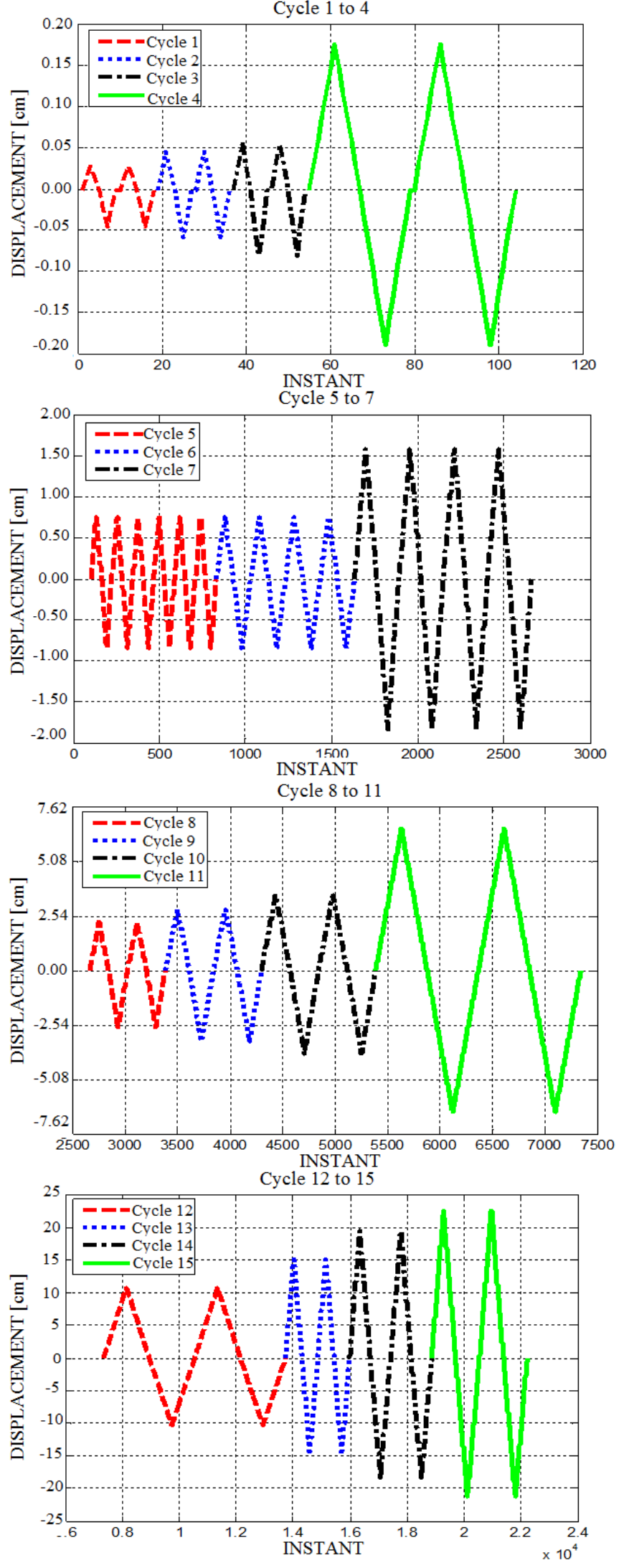

Fig. (6). Cyclic load. 


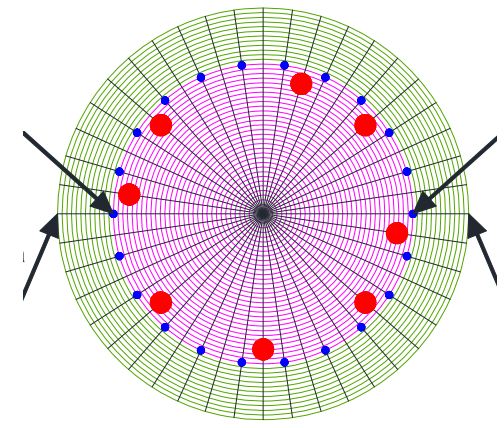

Fig (7). Critical points for stress-strain curves of concrete.

by the transverse reinforcement. In structural members, the unconfined concrete corresponds to the cover. It is presented below the stress-strain curves for the left outermost fiber of the cover concrete in the element E1 (see Fig. 2), for Concrete 02 and Concrete 07 models. The stress-strain curves on the right are not presented, since they only vary slightly.

The Concrete02 model considers tension. However, as the E1 element has great damage, it is not included. In contrast, the other elements (E2 to E7) do include this property. Loading cycles are linear, and unloading are bilinear (Fig. 8). This model considers the criteria proposed by Karsan-Jirsa and Yassin $[3,13]$.

The Concrete07, like the Concrete02, also considers tensile stresses and it was used in the same way. This model has the characteristic of having always positive compressive stresses against positive strains, this is because the Concrete 07 model considers the last deformed position by tension before reversing the load. From this end position, the counting of compression stress starts (Fig. 9). This model considers the criteria proposed by Chang-Mander and Waugh [6, 14].

It is observed that the envelope curve for the two models is very similar to each other. The difference lies in the loading and unloading curves.

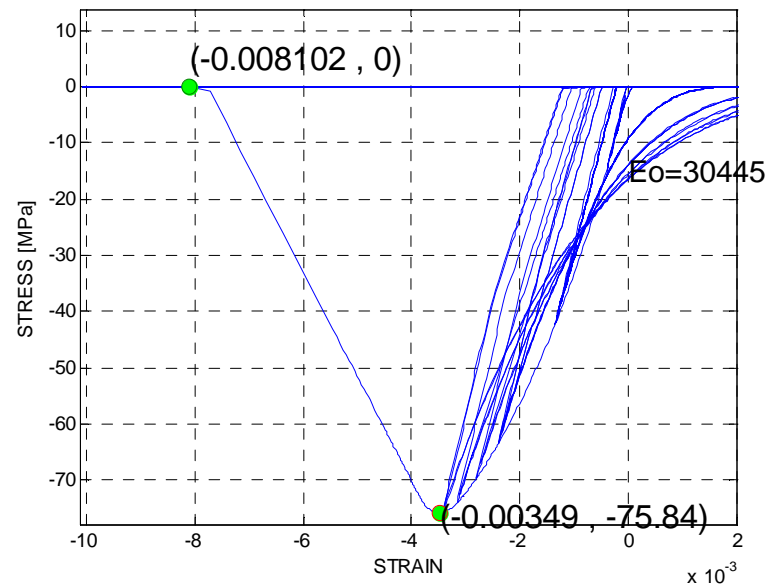

Fig. (9). Stress-strain curve in left outer fiber concrete cover of element E1, considering Concrete07.

\subsection{Confined Concrete}

In general, the confined concrete is one whose physical properties such as strength and deformation are greater than those of the unconfined, due to the presence of transverse reinforcement. In a structural element the confined concrete corresponds to that enclosed by transverse reinforcement.

As in the unconfined concrete, OpenSees allows to have stress-strain curves for the left outermost fiber confined concrete in the E1 element for Concrete02 and Concrete07 models. In the Concrete02 model, the envelope curve has a first parabolic section and then a straight line, until the residual stress, from which it has a horizontal line (Fig. 10). This model also considers the tensile strength of the concrete. The loading cycles are linear and unloading are bilinear. This model considers the criteria proposed by Karsan-Jirsa and Yassin [3, 13]. In Concrete07 model, the envelope has a curved shape, both before and after the section at which it is achieved maximum strength. It is observed that the shape of the envelope is different than Concrete02 model, since after

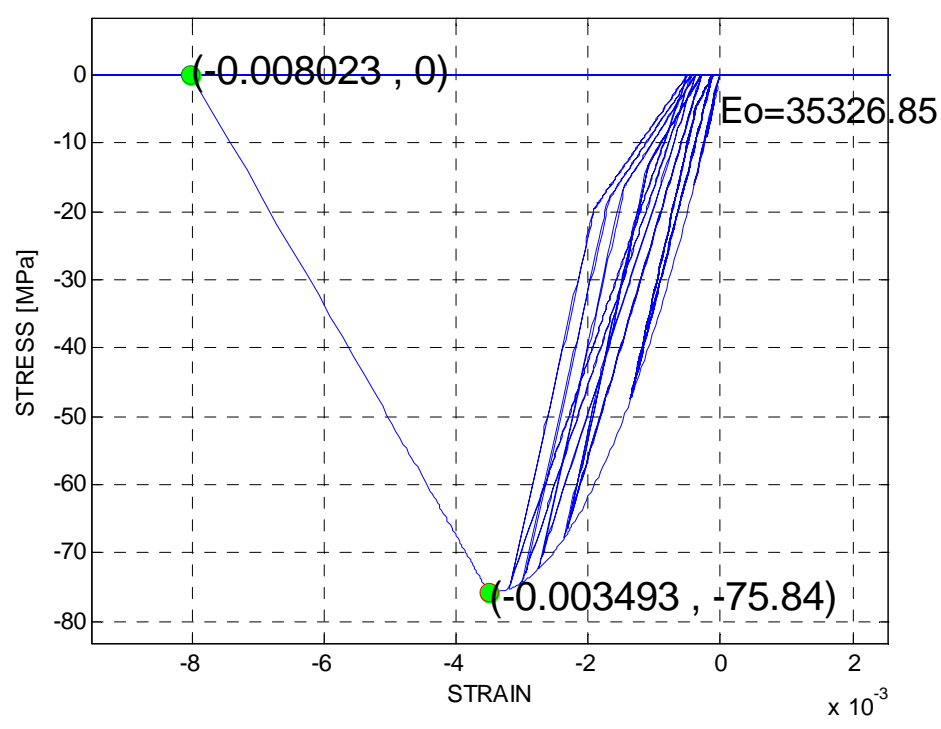

Fig. (8). Stress-strain curve in left outer fiber concrete cover of element E1, considering Concrete02. 


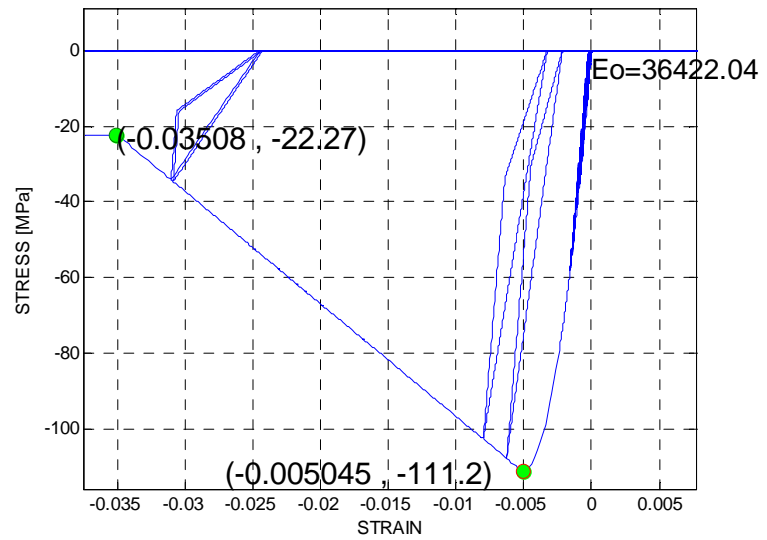

Fig. (10). Stress-strain curve in outermost left confined concrete fiber of element E1, considering Concrete02.

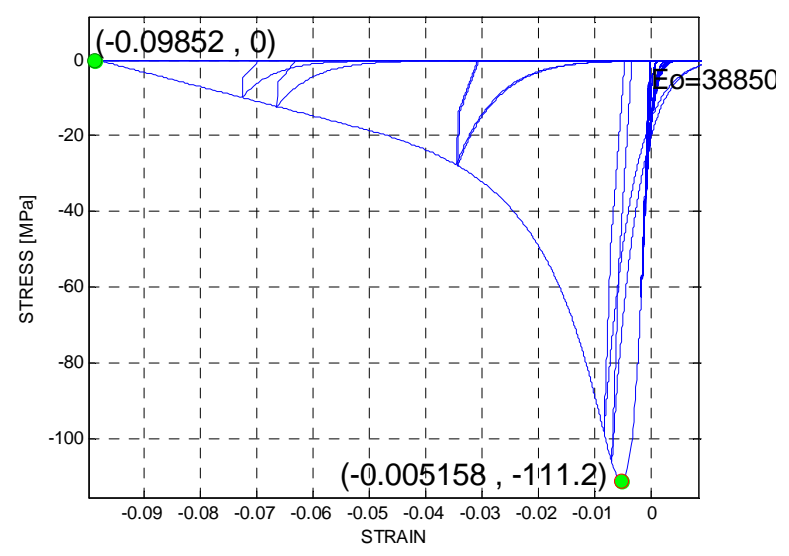

Fig. (11). Stress-strain curve in outermost left confined concrete fiber of element E1, considering Concrete 07 .

reaching the maximum stress, the curve does not reach a residual stress. As in the case of unconfined concrete, this model has the characteristic of having positive compressive stress at positive strains and considers the criteria proposed by Chang-Mander and Waugh $[6,14]$. It is observed that the envelope curve for the Concrete02 model is highly simplified while Concrete 07 envelope model represents more accurately the behavior of the confined concrete. There are also differences in the complexity of the loading and unloading curves.

\section{FORCE-DRIFT CURVES}

The hysteretic behavior of the structure under study can be observed in the force-drift curves. These curves are obtained by recording the history of lateral load and displacement at each instant in the 6 node (Fig. 2). In Fig. (12), force-drift curves of experimental tests on the specimen 9 obtained by Jellin [11] are shown, and also those obtained by use of OpenSees Concrete02 and Concrete07 models.

The force-drift curves look very similar to the experimental results. But to quantify which model has the best approximate, parameters such as secant modulus and hysteretic energy are used.

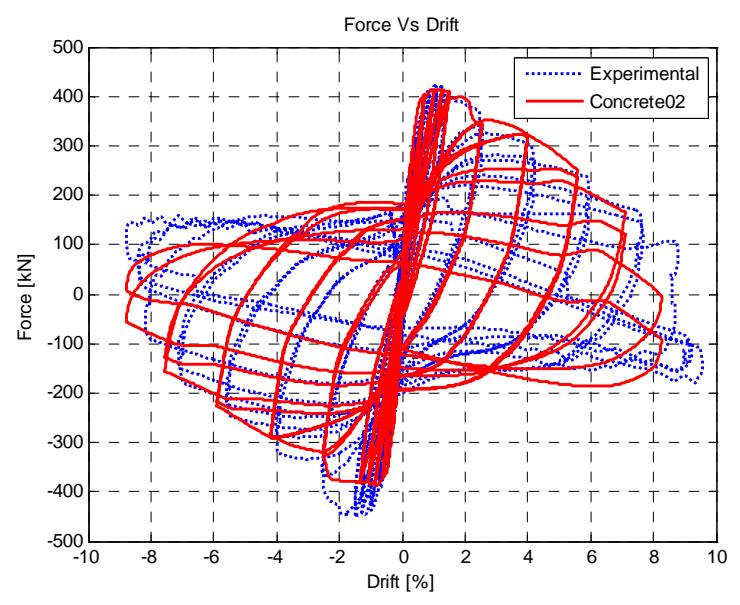

Fig. (12). (a). Force-drift curves.

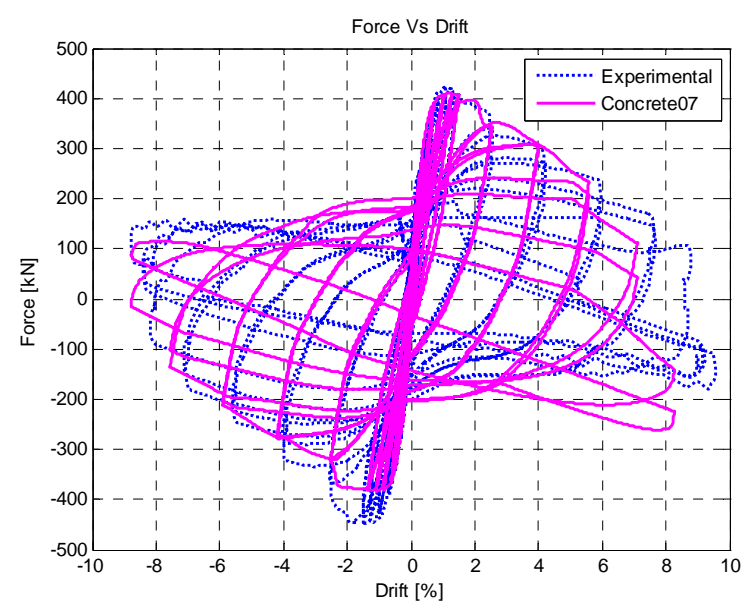

Fig. (12). (b). Force-drift curves.

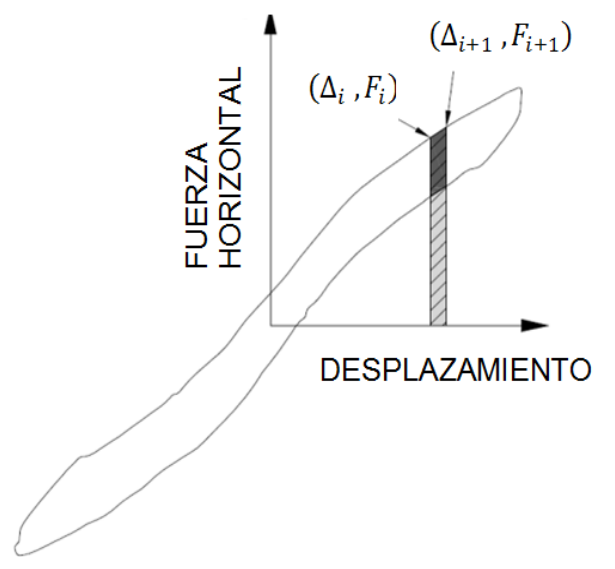

Fig. (13). Energy dissipated in one cycle.

\subsection{Energy Dissipation}

The hysteretic energy dissipated for one cycle is the area enclosed in the force-deformation curve of the cycle (Fig. 13).

Below is presented the expression used to calculate the energy dissipated in a given cycle. 


$$
E=\sum_{i}^{j} \frac{F_{i+1}+F_{i}}{2} *\left(\Delta_{i+1}-\Delta_{i}\right)
$$

where:

E: Energy dissipated in one cycle

\section{F: Cyclic Load.}

i: The first point of interest.

\section{$\mathrm{j}$ : Last point of interest.}

\section{$\Delta$ : Displacement of pile.}

From force-drift curves, it can be obtained forcedisplacement curves. They are identified per cycle, and the amount of dissipated energy is also determined in each of the cycles. Subsequently, a summatory is done and the total energy dissipated is calculated.
From load history shown in Fig. (6), it is seen that each cycle consists of a group of sub-cycles. In Fig. (14), the enclosed area in force-displacement experimental curves, for the two subcycles of cycle 8, is presented. In Fig. (15), the enclosed area in force-displacement Concrete02 model curves, for the two subcycles of cycle 8 , is presented.

Presented below is the dissipated energy, using the experimental data and the data obtained in OpenSees, with Concrete 02 and Concrete 07 models. It is taken as a reference value to the total dissipated energy obtained from experimental data to determine the difference (error).

It can be concluded from the results presented in Table $\mathbf{8}$, that the results of Concrete 02 and Concrete 07 are similar and very close to the experimental results, considering the total energy dissipated.
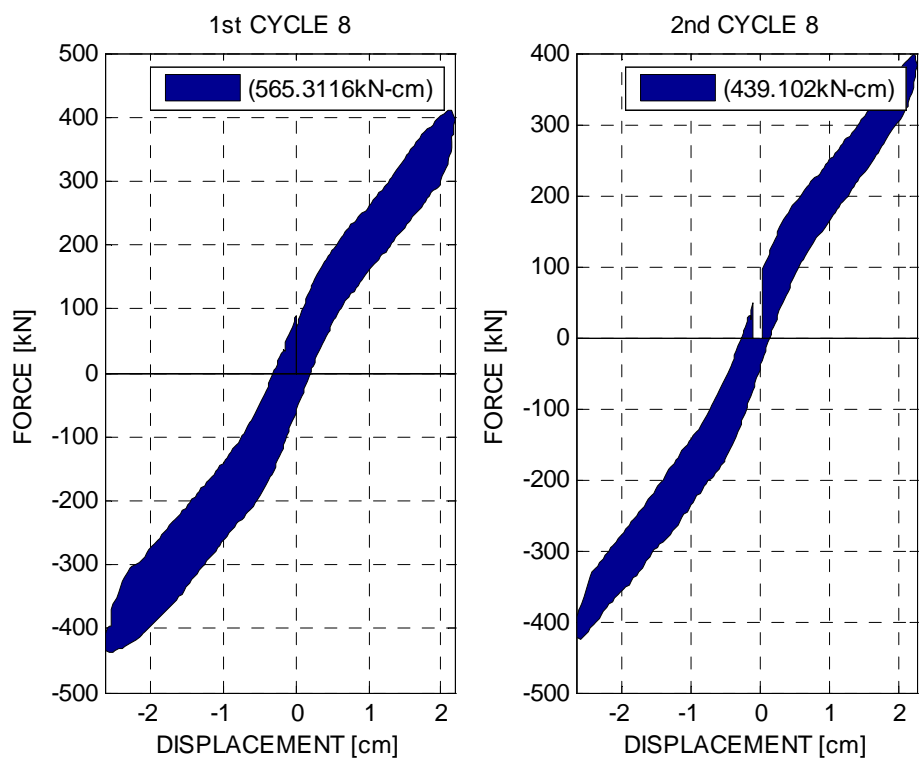

Fig. (14). Area enclosed by the force-displacement curve for cycle 8. (Experimental data).
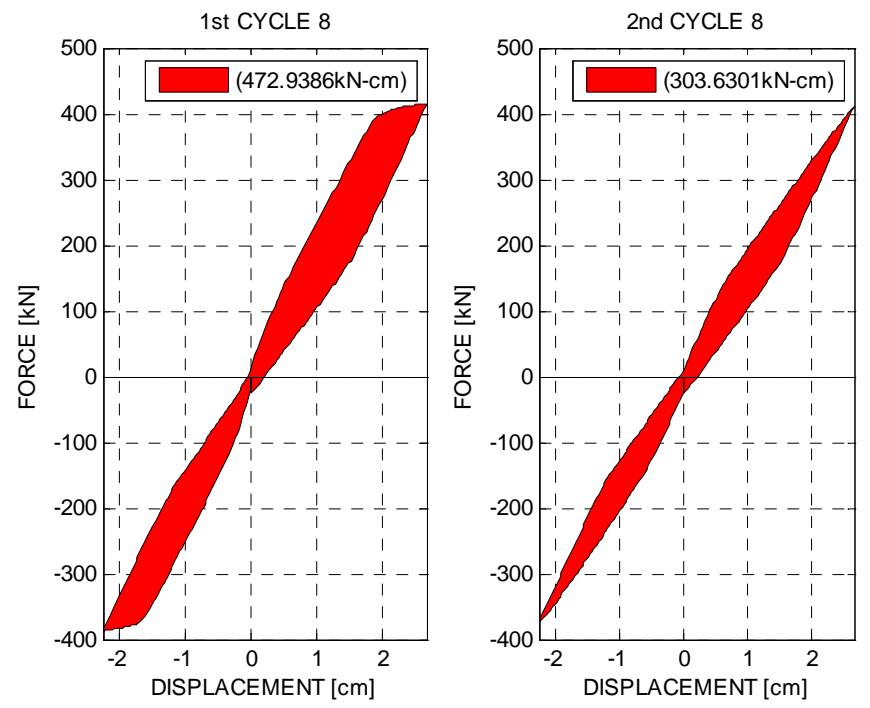

Fig. (15). Area enclosed by the force-displacement curve for cycle 8 . (Concrete02 model data). 
Table 8. Total energy dissipated for different models.

\begin{tabular}{|c|c|c|}
\hline Model & $\begin{array}{c}\text { Total } \\
\text { Energy Dissipated }[\mathbf{k N . c m}]\end{array}$ & Error \% \\
\hline \hline Experimental & 79266.7 & \\
\hline Concrete02 & 76440.2 & 3,57 \\
\hline Concrete07 & 76305.3 & 3,74 \\
\hline
\end{tabular}

\subsection{Secant Modulus}

From the force-displacement curves, a new parameter to verify the behavior of the models may be determine, for which two coordinate pairs must be identified, the first pair is minimal deformation and minimum force, while the sec- ond pair is maximum deformation and maximum force. The slope formed by the two coordinate pairs corresponds to the secant stiffness (Fig. 17).

The secant stiffness is obtained for each cycle, but as one cycle consists of several subcycles, firstly an average cycle should be determined, in which the secant stiffness is calculated. In Fig. (16), it is noted that cycle 7 consists of 4 subcycles. From these cycles, a corresponding average representative cycle was determined as shown in Fig. (17).

Finally, in Table 9, the secant modulus is presented, which is obtained in each average cycle from the experimental data and also for each type of concrete. Additionally, an error rate is determined using as reference value the secant modulus of the experimental data. It identifies in each cycle what concrete model is closest to the experimental results.
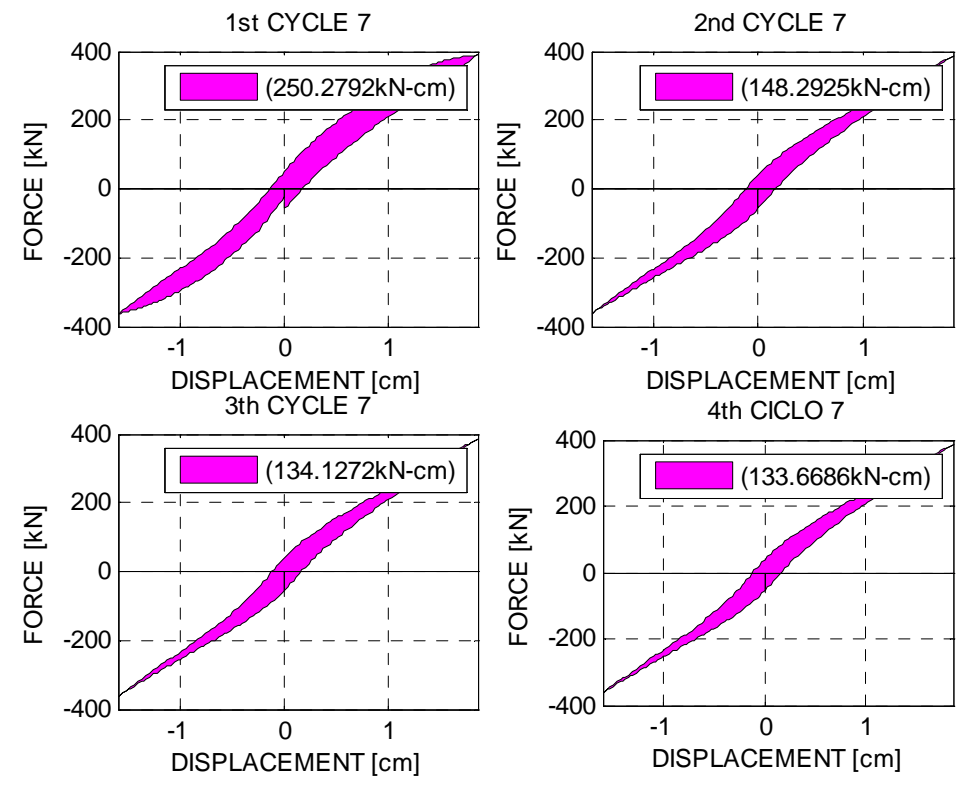

Fig. (16). Subcycles corresponding to Cycle 7 (Concrete07).

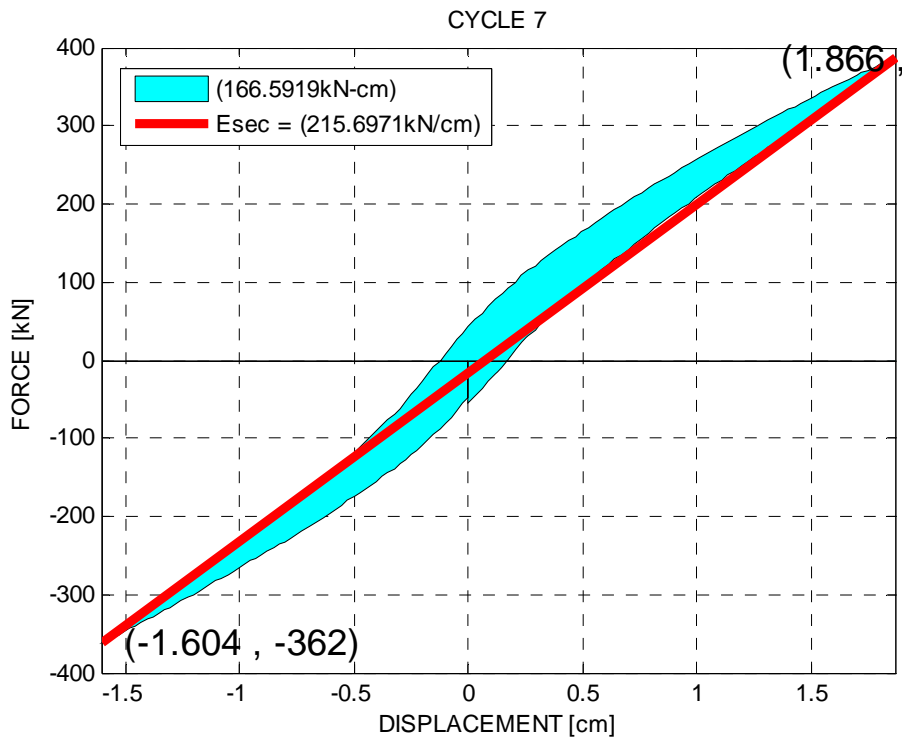

Fig. (17). Cycle 7 representative average and secant modulus (Concrete07). 
Table 9. Secant Modulus (Esec) per cycle and concrete model.

\begin{tabular}{|c|c|c|c|c|c|c|}
\hline \multirow{3}{*}{ Cycle } & \multirow{3}{*}{$\begin{array}{c}\text { Exp } \\
\text { Esec } \\
{[\mathrm{kN} / \mathrm{cm}]}\end{array}$} & \multicolumn{2}{|c|}{ Concrete02 } & \multicolumn{2}{|c|}{ Cocnrete07 } & \multirow{3}{*}{$\begin{array}{c}\text { Model with Minor } \\
\text { Error }\end{array}$} \\
\hline & & Esec & Error & Esec & Error & \\
\hline & & {$[\mathrm{kN} / \mathrm{cm}]$} & $\%$ & {$[\mathrm{kN} / \mathrm{cm}]$} & $\%$ & \\
\hline 1 & 852.27 & 546.33 & 35,90 & 511.55 & 39,98 & Concrete 02 \\
\hline 2 & 839.03 & 551.09 & 34,32 & 516.64 & 38,42 & Concrete 02 \\
\hline 3 & 785.60 & 550.72 & 29,90 & 516.24 & 34,29 & Concrete 02 \\
\hline 4 & 654.61 & 537.41 & 17,90 & 504.75 & 22,89 & Concrete 02 \\
\hline 5 & 327.31 & 344.67 & $-5,30$ & 326.02 & 0,40 & Concrete 07 \\
\hline 6 & 258.84 & 344.81 & $-33,21$ & 325.84 & $-25,89$ & Concrete 07 \\
\hline 7 & 212.10 & 221.40 & $-4,39$ & 215.70 & $-1,70$ & Concrete 07 \\
\hline 8 & 171.85 & 161.89 & 5,80 & 159.14 & 7,40 & Concrete 02 \\
\hline 9 & 138.46 & 128.30 & 7,33 & 127.32 & 8,04 & Concrete 02 \\
\hline 10 & 114.90 & 106.35 & 7,44 & 105.79 & 7,92 & Concrete 02 \\
\hline 11 & 59.16 & 53.69 & 9,26 & 53.34 & 9,83 & Concrete 02 \\
\hline 12 & 28.72 & 29.21 & $-1,72$ & 28.79 & $-0,26$ & Concrete 07 \\
\hline 13 & 15.90 & 18.30 & $-15,18$ & 17.44 & $-9,74$ & Concrete 07 \\
\hline 14 & 11.96 & 10.46 & 12,66 & 9.89 & 17,37 & Concrete 02 \\
\hline 15 & 7.55 & 5.97 & 20,83 & 7.16 & 5,09 & Concrete 07 \\
\hline
\end{tabular}

The Concrete 02 is the best agreement model to the experimental results. However, the results between Concrete0 7 and Concrete 02 are very close.

\section{DUCTILITY}

It is observed that there is considerable variation in ductility, depending on the stress-strain concrete model adopted in OpenSees. The parameters that allow to give an estimate of the ductility for both moderate damage to severe damage are detailed.

\subsection{Visible Cracking of the Concrete}

It is considered that the visible cracking of the concrete occurs when the outer fiber strain reaches 0.002 [15].

\subsection{First Yielding of the Steel Reinforcement}

It is considered that the first yield of steel is produced when the critical bar stress reaches the $95 \%$ of the yield stress. It is not considered the $100 \%$ of the yield stress because the results obtained in OpenSees, when working with cyclic loading, show that the yield stress of the steel is reduced by approximately $95 \%$.

\subsection{Minimal Spalling}

It is considered that the minimum spalling of the concrete cover occurs when the outermost fiber achieves its maximum strength.

\subsection{Substantial Spalling}

It is considered that the substantial spalling occurs when the outermost fiber of confined concrete reaches its residual strength.

\subsection{Parameters to Estimate Ductility Moderate Damage and Severe Damage}

In Figs. (18-20), the location of the parameters described above is presented to determine the ductility in moderate to severe damage, both to the left and to the right, and for the various models of concrete considered in this study. In these Figs, the order in which the parameters are produced and their coordinates, is identified as below:

\section{Order of occurrence (drift (\%), force $(\mathrm{kN})$ )}

The data presented in Fig. (19 and 20) allows to estimate the ductility moderate damage and severe damage, as presented in the following topics.

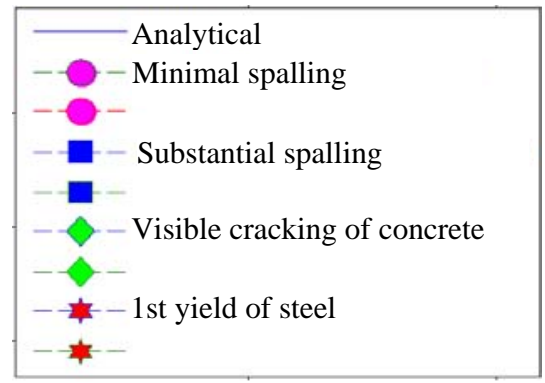

Fig. (18). Legend for Figs. (19 and 20). 


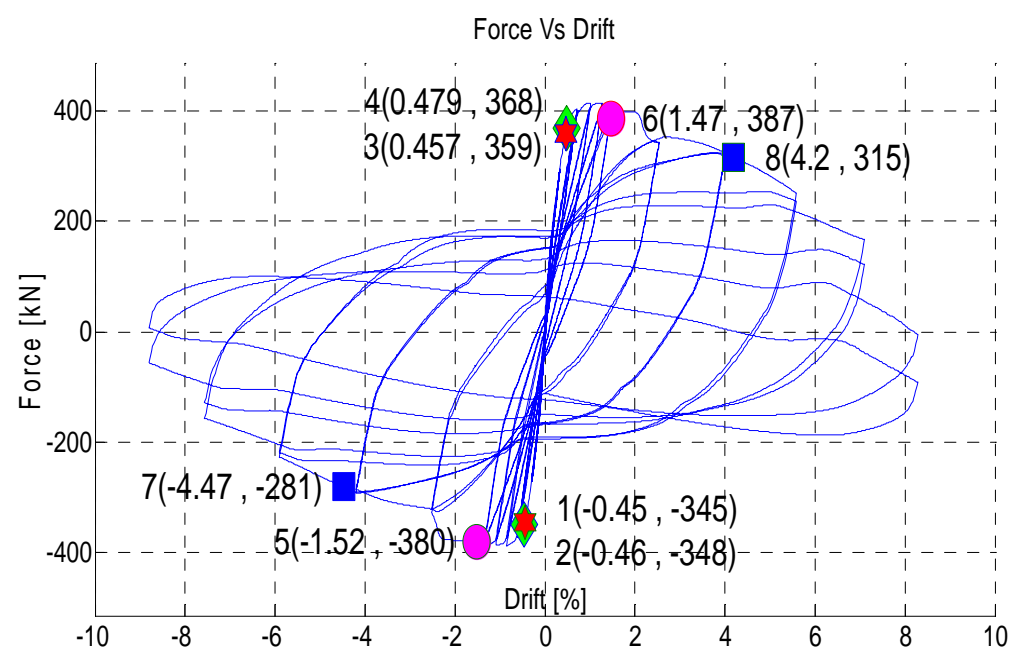

Fig. (19). Parameters considered in determining ductility in moderate and severe damage considering Concrete02.

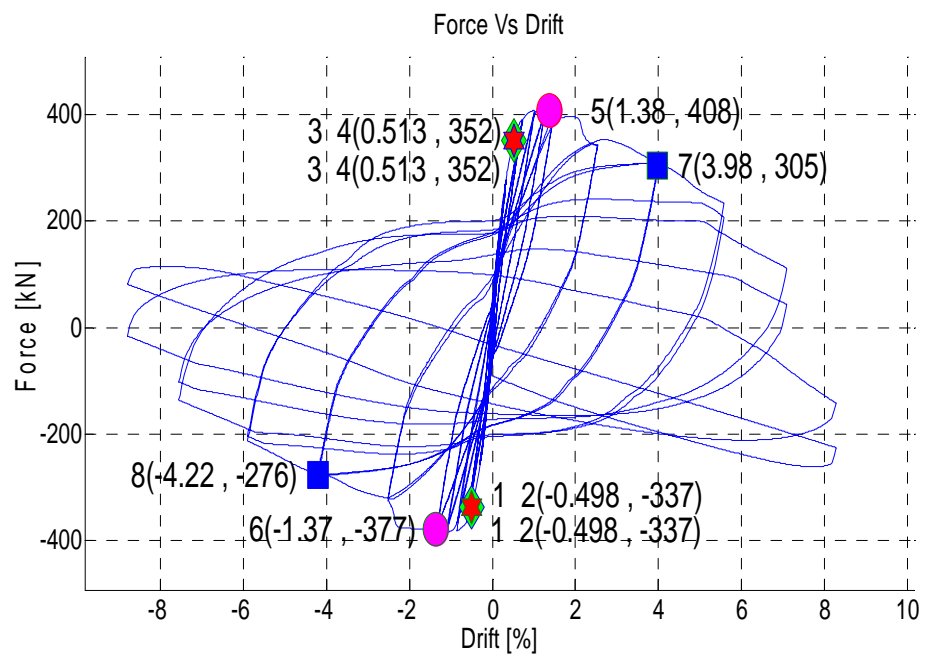

Fig. (20). Parameters considered in determining ductility in moderate and severe damage considering Concrete 07.

Tabla 10. Ductility in moderate damage.

\begin{tabular}{|c|c|c|c|c|c|c|}
\hline \multirow{2}{*}{ Tipe } & \multirow{2}{*}{$\frac{\operatorname{Exp}}{\mathrm{u}}$} & \multicolumn{2}{|c|}{ Concrete 02} & \multicolumn{2}{|c|}{ Concrete 07} & \multirow{2}{*}{$\begin{array}{c}\text { Model with Minor } \\
\text { Error }\end{array}$} \\
\hline & & $\mathbf{u}$ & Error\% & $\mathbf{u}$ & Error\% & \\
\hline drift (-) & 2,88 & 3,30 & $-14,55$ & 2,76 & 4,34 & Concrete 07 \\
\hline drift $(+)$ & 2,68 & 3,21 & $-19,75$ & 2,68 & $-0,17$ & Concrete07 \\
\hline
\end{tabular}

\subsection{Ductility at Moderate Damage}

The ductility at moderate damage considers the variables D1 and D2 presented in the following equation.

$\mu_{\text {moderate damage }}=\frac{D 1}{D 2}$

where D1 is the drift corresponding to the minimum spalling and D2 is the smallest drift between the first yield of steel and concrete visible cracking.

\subsection{Ductility at Severe Damage}

The ductility at severe damage considers the D3 and D2 variables presented in the following equation. $\mu_{\text {severe damage }}=\frac{D 3}{D 2}$

where D3 is drift corresponding to substantial spalling and D2 is the smallest drift between the first yield of steel and concrete visible cracking.

From the results presented in Tables $\mathbf{1 0}$ and 11, it can be seen that the ductility obtained with the Concrete 07 model approximates better the experimental results.

\section{RUNTIME}

The number of seconds that OpenSEES program uses to run, trying to model the structure of this article (Fig. 2) was 
Tabla 11. Ductility in severe damage.

\begin{tabular}{|c|c|c|c|c|c|c|}
\hline \multirow{2}{*}{ Tipe } & Exp & \multicolumn{2}{|c|}{ Concrete 02 } & \multicolumn{2}{|c|}{ Concrete 07 } & $\begin{array}{c}\text { Model with Minor } \\
\text { Error }\end{array}$ \\
\cline { 2 - 7 } & $\mathbf{u}$ & $\mathbf{u}$ & Error\% & u & Error\% & $-9,37$ \\
\hline \hline drift (-) & 7,74 & 9,72 & $-25,59$ & 8,46 & $-0,40$ & Concrete07 \\
\hline drift (+) & 7,72 & 9,18 & $-18,90$ & 7,75 & Concrete 07 \\
\hline
\end{tabular}

Table 12. Runtime.

\begin{tabular}{|c|c|}
\hline Model & Runtime [s] \\
\hline \hline Concrete02 & 292 \\
\hline Concrete07 & 544 \\
\hline
\end{tabular}

measured, considering Concrete02 and Concrete07 models. The runtimes are presented in Table $\mathbf{1 2}$.

The model with the lowest runtime is Concrete02. The Concrete 07 model is 1.86 times the Concrete 02 model runtime.

\section{CONCLUSION}

The hysteresis curves obtained when considering Concrete 02 and Concrete 07 models are similar to the experimental results. This behavior can be demonstrated with the results of hysteretic energy dissipated and secant modulus in each cycle presented in this study. Note that the variation between Concrete 02 and Concrete 07 in terms of the hysteresis curves is minimal.

However, the variation between the results of ductility is significant between the two models. This is because the instant in which the adopted parameters occurs varies between Concrete 02 and Concrete 07 models, due to the difference of the shapes of both the envelope curves as the curves for loading and unloading.

The Concrete07 model gives more approximate results to the experimental, considering the ductility as a comparison parameter. But this approach causes additional runtime, it is 1.86 times the Concrete 02 model runtime. However, the hysteretic energy estimates and secant modulus obtained using the two models are similar.

Estimates of moderate and minor damage have been related successfully with critical deformations in stress-strain curves of concrete.

The point of first yielding of the steel was modified to take into account the loss of resistance during each cycle.

This study was limited to verifying the behavior of concrete models proposed in OpenSees. The steel models used are ReinforcingSteel steel, for steel connecting bars, and ElasticPerfectlyPlastic for prestressing steel. A next paper will study the effect of using different models of reinforcing steel that are available in OpenSees.

These results would be applied for accurate estimates of lateral displacements in wharf structures and will lead to recommendations such as the amount of lateral reinforcement needed to better control the structures vulnerability.

\section{CONFLICT OF INTEREST}

The authors confirm that this article content has no conflict of interest.

\section{ACKNOWLEDGEMENTS}

Declared none.

\section{REFERENCES}

[1] P. Caiza, and Y. D. Sosa, "Estudio Comparativo de Modelos de Fibras con Diferentes Materiales de Tipo Hormigón Usados en OpenSEES", Tercera Jornada de Investigación Cientifica Desde las Aulas, vol. 2, no. 1, pp. 108-129, 2013.

[2] B. P. Sinha, K. H. Gerstle, and L. G. Tulin, "Stress-strain relations for concrete under cyclic loading," ACI Journal Proceedings, vol. 61, no. 2, pp. 195-211, 1964.

[3] I. D. Karsan, and J. O. Jirsa, "Behavior of concrete under compressive loading," Journal of the Structural Division, vol. 95, no. 12, pp. 2543-2564, December 1969.

[4] D. Z. Yankelevsky, and H. W. Reinhardt, "Model for cyclic compressive behavior of concrete," Journal of Structural Engineering, vol. 113, no. 2, pp. 228-240, 1987.

[5] J. B. Mander, M. J. N. Priestley, and R. Park, "Theoretical stressstrain model for confined concrete," Journal of Structural Engineering, vol. 114, no. 8, pp. 1804-1825, 1988.

[6] G. Chang, and J. Mander, "Seismic Energy Based Fatigue Damage Analysis of Bridge Columns: Part I- Evaluation of Seismic Capacity", NCEER Technical Report 94-0006, National Center for Earthquake Engineering and Research, State University of New York at Buffalo, NY, USA, 1994.

[7] J. E. Martínez-Rueda, and A. S. Elnashai, "Confined concrete model under cyclic load," Materials and Structures/Materiaux et Constructions, vol. 30, no. 197, pp. 139-147, 1997.

[8] B. Y. Bahn, and C. T. Hsu, "Stress-strain behavior of concrete under cyclic loading," ACI Materials Journal, vol. 95, no. 2, pp. 178-193, 1998.

[9] M. Mansour, and T. T. C. Hsu, "Behavior of reinforced concrete elements under cyclic shear II: In: Theoretical model," Journal of Structural Engineering, vol. 131, no. 1, pp. 54-65, 2005.

[10] J. F. Sima, P. Roca, and C. Molins, "Modelo constitutivo para el hormigón sometido a cargas cíclicas”. In: 3er Congreso Nacional de Ingeniería Sísmica. CIMNE - Centre Internacional de Métodes Numérics en Enginyeria, 2007, pp. 1031-1046.

[11] A. Jellin, "Improved Seismic Connections for Pile-Wharf Construction," MS thesis, University of Washington, Washington, USA, 2008.

[12] P. Caiza, "Seismic Modeling, Analysis and Design of Structural Concrete Pile-Deck Connections," PhD dissertation, University of Illinois, Illinois, USA, 2013.

[13] M. H. M. Yassin, "Nonlinear Analysis of Prestressed Concrete Structures under Monotonic and Cyclic Loads", PhD dissertation, University of California, Berkeley, California, USA, 1994. 
[14] J. Waugh, "Nonlinear analysis of T-shaped concrete walls subjected to multi-directional displacements," $\mathrm{PhD}$ dissertation, Iowa State University, IA, 2009.
[15] M. J. N. Priestley, G. M. Calvi, and M. J. Kowalsky, DisplacementBased Seismic Design of Structures, IUSS Press, Pavia, Italy, 2007, p. 720 .

Received: October 30, 2014

(C) Sosa and Caiza; Licensee Bentham Open.

This is an open access article licensed under the terms of the Creative Commons Attribution Non-Commercial License (http://creativecommons.org/licenses/ by-nc/3.0/) which permits unrestricted, non-commercial use, distribution and reproduction in any medium, provided the work is properly cited. 